\title{
IFASCON 2019 New Delhi
}

\author{
Aug. 29 to SeP. 12019
}

Journal of Foot and Ankle Surgery (Asia Pacific) (2019): 10.5005/jp-journals-10040-1109

The 32nd Annual Conference of the Indian Foot and Ankle Society was held in New Delhi from Aug. 29, 2019 to Sep. 1, 2019.

The event had many firsts, including cadaver workshops, a full day rehab workshop, guest nation, IFAS quiz and fellowship interviews conducted during the conference. We welcomed Nepal as the first guest nation with delegates and faculty from Nepal participating enthusiastically in the event. Interviews were conducted for fellowship opportunities at eight international and two national foot and ankle centers.

The total registrations for the main conference were more than 350; there were 60 separate registrations for the PG course and above 200 registrations for the rehab workshop.

\section{Aug. 29, 2019}

The event started on Aug. 29, 2019 with 3 full-day preconference workshops-two foot and ankle cadaver courses in collaboration with AIIMS JPN Apex Trauma Centre and Maulana Azad Medical College, and a foot and ankle rehab course at Indian Spinal Injuries Centre.

The cadaver workshops were fully booked well before the event and included well-known national and international foot and ankle experts as faculty. The scientific content and hands-on experience were well appreciated by the delegates and faculty alike.

The foot and ankle rehab workshop was a roaring success with paid delegates in excess of 200 learning about the assessment, concepts, and practical applications of various rehab techniques. The course had rehab professionals, orthopedic surgeons, and orthotics as participants with two international faculty and renowned national faculty.

\section{Aug. 30, 2019}

The main conference kicked off at Le Meridien on Aug. 30, 2019 at 8 am with six back-to-back live surgeries transmitted to the venue from Indian Spinal Injuries Centre. These showcased the whole gamut of foot and ankle practice, including severe hallux valgus, neglected lisfranc injury, hindfoot arthritis, ankle arthroscopic fusion, and Achilles tendo reconstruction with FHL transfer.

This was followed by four sessions of case presentations by faculty and delegates, and a breakout session, which included a guest nation lecture, an interactive radiology session, and a motivational talk. The day ended with a very lively IFAS quiz with eight teams of two persons each pitted against each other. The winners received an IFAS champions trophy and a foot and ankle textbook each.

More than 60 posters were put up by the delegates, which were evaluated by the judges, and the winner received a textbook by an international faculty.

The social event of the evening was a faculty dinner at Delhi Gymkhana Club. The faculty were felicitated by the organizers.

\section{Aug. 31, 2019}

The third day started with a 1-hour masterclass on foot and ankle examination. This was followed by 12 scientific sessions in two parallel halls encompassing the whole variety of elective and trauma foot and ankle pathologies. These included didactic lectures, video lectures, debates, and case-based discussions.

The pre-lunch session had orations given by Dr Michael Coughlin (Ram Janam Sulakshna Pandey Oration) and Dr Sampat Dumbre Patil (Past President Oration). The general body meeting of the Indian Foot and Ankle Society was also held on this day.

At the end of the scientific sessions, there was a special session dedicated to running and fitness, followed by the inauguration and banquet dinner. The chief guest for the inauguration was Major DP Singh, a Kargil veteran and India's first blade runner, his motivating lecture in the running session was concluded with a standing ovation by the audience.

\section{SEP. 1, 2019}

Three parallel halls were running on this day, with scientific sessions, free papers, and PG course running at the same time. Two gold medal sessions for free papers were conducted, more than 30 free papers were presented, and winners were awarded premium foot and ankle textbooks by international authors. The event concluded at lunchtime after the valedictory function and distribution of prizes.

On the whole, the event was an outstanding success. The feedback received from around $100+$ delegates, $85 \%$ rated the event 4 or higher on a $0-5$ scale. 


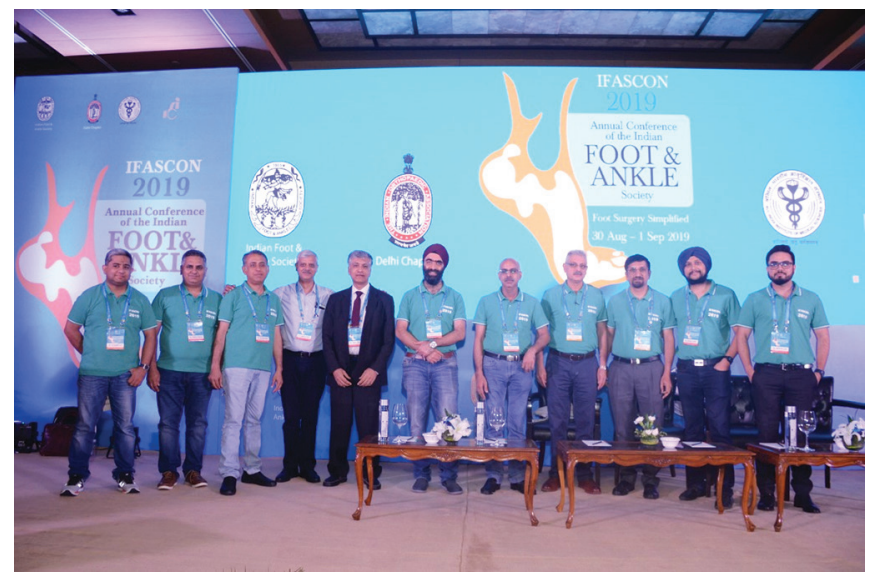

Fig. 1: Team IFASCON 2019

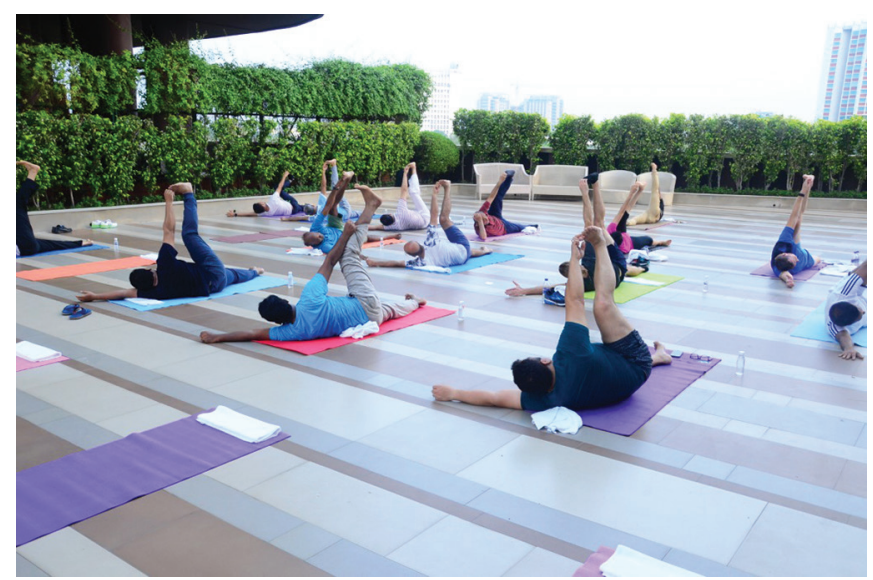

Fig. 3: Morning Yoga session

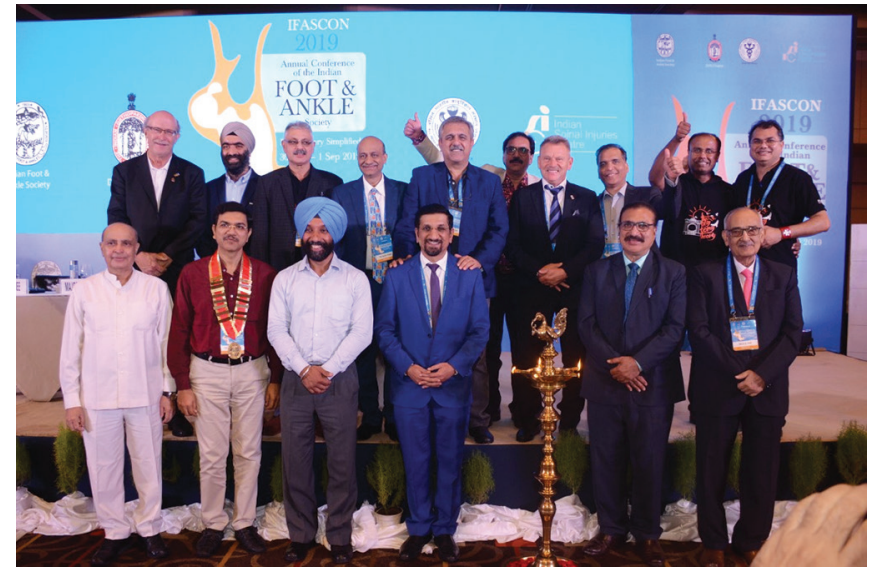

Fig. 5: International and national faculty members at the inaugural ceremony

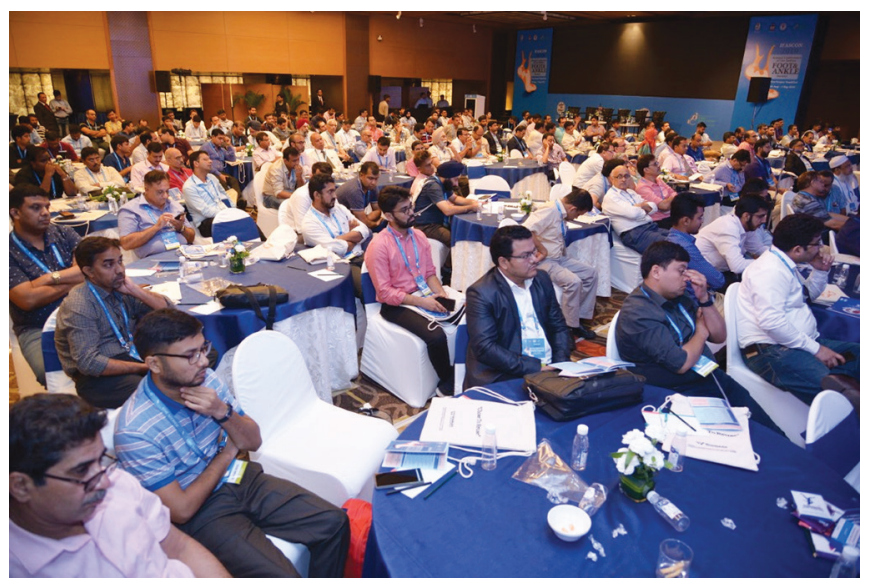

Fig. 2: Delegates listening in rapt attention

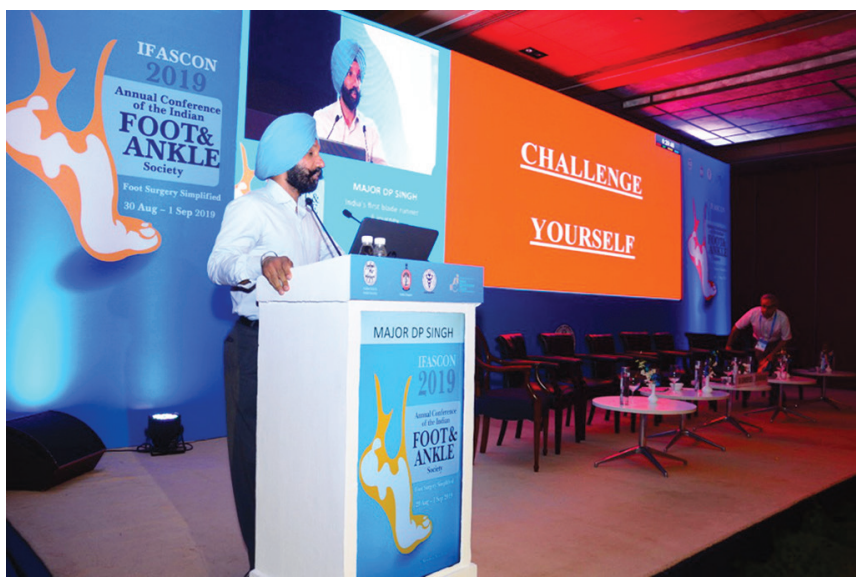

Fig. 4: Maj D P Singh, India's first blade runner at IFASCON 2019

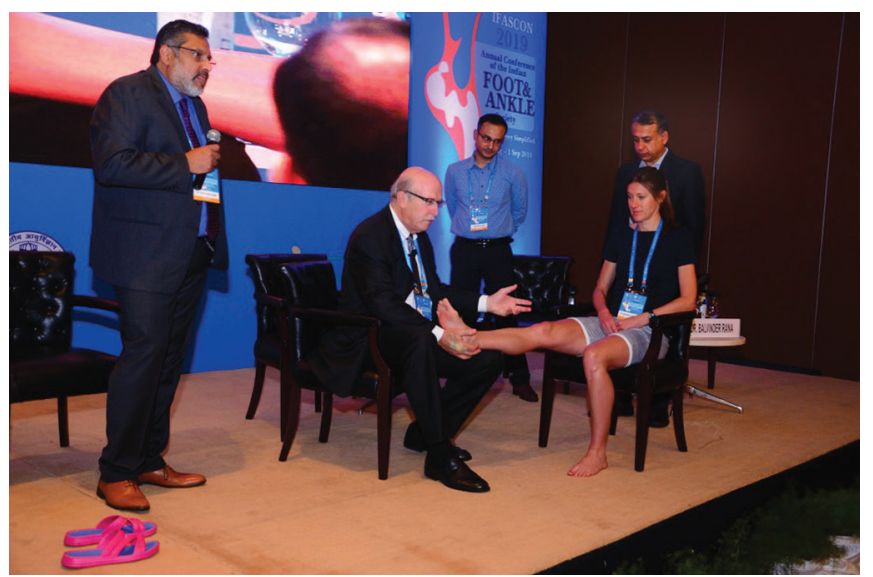

Fig. 6: Prof Michael Coughlin and Prof Kartik Hariharan teaching the examination of foot and ankle
Dr Maninder S Singh Organizing Chairman
Dr Harpreet Singh Organizing Secretary
Report compiled by Dr Inderjit Singh Co-organizing Secretary 